\title{
Retinol binding protein-4 is associated with TNF- $\alpha$ and not insulin resistance in subjects with type 2 diabetes mellitus and coronary heart disease
}

\author{
Nasser M. Al-Daghri*, Omar S. Al-Attas, Majed Alokail, Hossam M. Draz, Ahmed Bamakhramah and \\ Shaun Sabico \\ Biochemistry Department, College of Science, King Saud University, Riyadh, Saudi Arabia
}

\begin{abstract}
We studied the association between RBP4 and various markers related to insulin resistance and diabetic complications as well as inflammatory markers in Saudi population suffering from type 2 diabetes and coronary heart disease. Patients with type 2 diabetes were divided into 3 groups according to the type of treatment and involvement of coronary artery disease. Serum RBP4, TNF- $\alpha$, insulin, CRP, resistin, leptin and adiponectin were analysed in all samples. RBP4 levels increased significantly in the group of diabetic subjects treated with oral hypoglycemic agents and diabetic patients with coronary heart disease (30.2 \pm $11.8 ; 33.4 \pm 13.6$ respectively), while there was no significant change in the other group for diabetic subjects on low-carbohydrate diet $(25.1 \pm 10.9)$ compared to control group $(22.6 \pm 9.5)$. RPB4 levels were positively correlated with TNF- $\alpha$ in the group of diabetic subjects on oral hypoglycemic agents and diabetic patients with coronary heart disease $(r=0.52, P<0.05 ; r=$ $0.58, P<0.05$ respectively). No correlations were found between RBP4 levels and insulin resistance in all studied groups. Our findings suggest that serum RBP4 levels is associated with pro-inflammatory cytokine (TNF- $\alpha$ ) and is not associated with insulin resistance among patients with type 2 diabetes and coronary heart disease.
\end{abstract}

Keywords: Retinol-binding protein 4 , TNF- $\alpha$, insulin resistance, type 2 diabetes, coronary heart diseases

Abbreviations: CHD, coronary heart disease; CRP, C-reactive protein; DM, diabetes mellitus; OHG, oral hypoglycemic agents; HOMA-IR, homeostasis model assessment of insulin resistance; Glut4, glucose transporter 4; RBP4, retinol-binding protein 4; TNF- $\alpha$, tumor necrosis factor-alpha

\section{Introduction}

Obesity, characterized by excess accumulation of adipose tissue, is the most common risk factor for the metabolic syndrome, a cluster of dyslipidemia, insulin resistance, hypertension, and atherosclerosis [1].

RBP4 is the specific carrier protein for retinol (vitamin A) in the blood. It is not a recently described

* Corresponding author: Nasser M. Al-Daghri, College of Science Biochemistry Department, King Saud University PO Box 2455, Riyadh, Saudi Arabia. Tel.: +966 14675939; Fax: +966 14675931; E-mail: aldaghri2000@hotmail.com. protein; one of the earliest descriptions appeared back in 1987 [2]. RPB4 secreted primarily from the liver and adipose tissue, was recently identified as a novel adipokine which is involved in the modulation of glucose metabolism [3]. Expression of RBP4 was elevated in mice adipose tissue lacking GLUT4, which results in insulin resistance in muscle and the liver [3, 4]. However, data in humans are controversial and less clear, some previous studies have shown that RBP4 levels were increased in the subjects with type 2 diabetes (T2DM) [5,6]. Recently, Graham and colleagues reported that increased levels of RBP4 were associated with the magnitude of insulin resistance in subjects 
with obesity, impaired glucose tolerance or T2DM [7]. In contrast, other observations from obese subjects suggest a differential regulation of RBP4 in animals and humans and also a different physiological role [8]. It has been hypothesized that elevated RBP4 levels in type 2 diabetic subjects may reflect elevated levels of LDL cholesterol instead of insulin resistance [8,9]. It has been reported that circulating RBP4 concentrations remain similar in lean, overweight, and obese women, suggesting that methodological differences including techniques used and differences in the population studied may account for the discrepancies [8]. Moreover, plasma RBP4 levels were highly correlated with obesity and insulin resistance in some previous studies [7-10], while few showed no relationship between plasma RBP4 and insulin resistance [8-11]. Inflammatory molecules including TNF- $\alpha$ are expressed and up-regulated in adipose tissue of the obese state including type 2 diabetes [12]. In human adipocytes, RBP4 production is down regulated by the pro-inflammatory cytokine TNF- $\alpha$ [13].

Clearly, considerable work is required to study the role of RBP4 in obesity, diabetes and cardiovascular disease. Accordingly, the aim of this study is to investigate the association between RBP4 and various markers related to insulin resistance and diabetic complications as well as inflammatory markers in Saudi population suffering from type 2 diabetes and coronary heart disease.

\section{Methodology}

\subsection{Patients and methods}

A total of 137 adult Saudis who were attending the outpatient department of the Diabetes Research Unit of King Abdul-Aziz University Hospital, Riyadh, Kingdom of Saudi Arabia were recruited in this crosssectional study. Each participant was given a generalized questionnaire which included personal information and past and present medical history. Four different cohorts of patients were studied based on the clinical findings (Clinical history, ECG tracing, list of medications, glycemic control, etc.) of the physician: (1) 31 patients with type 2 diabetes on low-carbohydrate diet (DM on diet); (2) 38 patients with type 2 diabetes on oral hypoglycemic agents (DM on OHG); (3) 29 patients with type 2 diabetes and CHD (DM+CHD); (4) besides 39 healthy controls without history of CHD or type 2 diabetes. Patients of group 2 were on met- formin and thiazolidinediones. Aside from the $\mathrm{OHG}$ mentioned, patients of group 3 were on lipid-lowering agents (statins) and anti-hypertensive medications. Diagnosis of diabetes was established if the patient had: 1) prior diagnosis of type 2 diabetes mellitus; 2) fasting plasma glucose (FPG) was $>7.0 \mathrm{mmol} / \mathrm{L}$ and/or if taking oral hypoglycemics; 3) clinical manifestations of diabetes (polydipsia, polyphagia, polyuria) and/or 2-hour oral glucose tolerance test (OGTT) $\geqslant$ $11.1 \mathrm{mmol} / \mathrm{L}$ for asymptomatic patients with elevated FPG. Subjects with HBA1c $>11 \%$ were excluded from the study. All participants underwent complete physical examination, including blood pressure, height, weight, waist and hip measurements. BMI was calculated as weight in kilograms divided by height in squared meters. They also submitted fasting blood samples, the lipid profiles of which were measured, including fasting plasma glucose under routine laboratory procedures.

Serum RBP4 was measured by an enzyme-linked immunosorbent assay (Immun-Diagnostik AG, Bensheim, Germany). Serum insulin was analysed by sandwich ELISA (BioSource Europe S.A., Nivelles, Belgium). Homeostasis model assessment-insulin resistance (HOMA-IR) was derived using the HOMA equation [14]. Serum resistin and adiponectin were measured using the commercially available ELISA kit by Linco Research (St Charles MO-63304-USA). Serum TNF- $\alpha$ and leptin were measured by ELISA kit (R\&D systems, Minneapolis, USA). Serum CRP were analysed by sandwich ELISA (Immundiagnostik AG, Bensheim, Germany). Written consent and approval were obtained prior to being included in the study. Ethical approval was granted by the Ethics Committee of the College of Medicine and Research center of King Saud University, Riyadh, Kingdom of Saudi Arabia, prior to the research proper.

\subsection{Statistical analysis}

SPSS version 11.5 (Chicago, Illinois) for Windows was used for the statistical evaluation of the results obtained. All data are presented as mean \pm SD since all variables of interest were normally distributed. Analysis of variance was performed to compare the variables in the studied groups. Post-hoc analysis (Bonferroni) was also done to compare individual groups. Simple and partial correlation coefficients between the variables were determined and multiple regression analysis was performed to determine the relationships between the variables of interest. Power calculations were also 
Table 1

Clinical characteristic of subjects

\begin{tabular}{lcccc}
\hline Parameter & Control & DM on OHG & DM + CHD & DM on diet \\
\hline$N$ & 39 & 38 & 29 & 31 \\
$M / F$ & $14 / 17$ & $15 / 23$ & $14 / 15$ & $19 / 20$ \\
Age $($ years $)$ & $42.1 \pm 10.1$ & $51.7 \pm 9.5^{*}$ & $56.0 \pm 9.9^{*}$ & $47.0 \pm 7.3^{* *}$ \\
BMI $\left(\mathrm{kg} / \mathrm{m}^{2}\right)$ & $29.0 \pm 4.5$ & $32.1 \pm 5.8$ & $32.7 \pm 5.9$ & $29.7 \pm 6.2$ \\
Systolic BP $(\mathrm{mmHg})$ & $112.6 \pm 17.2$ & $132.3 \pm 24.7^{*}$ & $128.6 \pm 24.3^{*}$ & $115.5 \pm 21.3 !^{* *}$ \\
Diastolic BP $(\mathrm{mmHg})$ & $84.3 \pm 15.0$ & $82.1 \pm 10.5$ & $83.8 \pm 15.4$ & $88.0 \pm 15.9$ \\
Waist $(\mathrm{cm})$ & $109.4 \pm 22.0$ & $106.0 \pm 15.1$ & $118.7 \pm 27.4$ & $111.8 \pm 19.5$ \\
Hips $(\mathrm{cm})$ & $91.4 \pm 10.8$ & $101.5 \pm 11.9$ & $104.1 \pm 25.7^{*}$ & $92.9 \pm 15.4$ \\
Glucose $(\mathrm{mmol} / \mathrm{L})$ & $5.0 \pm 0.9$ & $9.4 \pm 3.7^{*}$ & $9.8 \pm 3.3^{*}$ & $7.3 \pm 3.0^{*}$ \\
Insulin $(\mathrm{IU} / \mathrm{ml})$ & $17.3 \pm 12.9$ & $24.1 \pm 19.7$ & $15.1 \pm 8.8$ & $20.6 \pm 11.5$ \\
HOMA-IR & $3.9 \pm 2.6$ & $8.3 \pm 5.1^{*}$ & $6.8 \pm 3.8^{*}$ & $6.7 \pm 3.9^{*}$ \\
Triglycerides $(\mathrm{mmol} / \mathrm{L})$ & $1.4 \pm 0.7$ & $2.1 \pm 1.6$ & $2.0 \pm 0.8$ & $1.6 \pm 1.0$ \\
HDL-cholesterol $(\mathrm{mmol} / \mathrm{L})$ & $1.1 \pm 0.3$ & $1.07 \pm 0.4$ & $1.1 \pm 0.6$ & $1.4 \pm 0.7$ \\
LDL-cholesterol $(\mathrm{mmol} / \mathrm{L})$ & $3.2 \pm 1.0$ & $2.9 \pm 0.9$ & $2.4 \pm 0.7^{*}$ & $2.8 \pm 0.8$ \\
Total cholesterol $(\mathrm{mmol} / \mathrm{L})$ & $4.4 \pm 1.8$ & $4.4 \pm 2.1$ & $3.9 \pm 1.8$ & $4.7 \pm 1.3$ \\
RBP4 $(\mathrm{mg} / \mathrm{L})$ & $22.6 \pm 9.5$ & $30.2 \pm 11.8^{*}$ & $33.4 \pm 13.6^{*}$ & $25.1 \pm 10.9$ \\
Leptin $(\mathrm{pg} / \mathrm{ml})$ & $21.7 \pm 13.2$ & $23.3 \pm 16.7$ & $23.7 \pm 15.6$ & $16.3 \pm 12.0$ \\
Adiponectin $(\mu \mathrm{g} / \mathrm{ml})$ & $8.1 \pm 3.5$ & $11.7 \pm 6.8^{*}$ & $11.2 \pm 6.0^{*}$ & $8.7 \pm 4.4$ \\
Resistin $(\mathrm{ng} / \mathrm{ml})$ & $16.8 \pm 7.6$ & $16.0 \pm 7.6$ & $17.8 \pm 8.3$ & $14.4 \pm 6.4$ \\
CRP $(\mu \mathrm{g} / \mathrm{ml})$ & $3.1 \pm 2.9$ & $3.7 \pm 3.8$ & $3.6 \pm 3.2$ & $4.0 \pm 4.1$ \\
TNF- $\alpha(\mathrm{pg} / \mathrm{ml})$ & $6.5 \pm 2.1$ & $5.1 \pm 1.5$ & $4.4 \pm 2.1^{*}$ & $5.0 \pm 2.2$ \\
\hline Dataresented as $)$ & & &
\end{tabular}

Data presented as mean $\pm \mathrm{SD}$; ${ }^{*}$ denotes significance compared to control; !denotes significance compared to DM on OHG; ${ }^{* *}$ significant compared to DM + CHD.

$\mathrm{DM}+\mathrm{CHD}$ : diabetic patients with coronary heart disease.

DM on OHG: diabetic patients treated with oral hypoglycemic agents.

DM on diet: diabetic patients treated with low-carbohydrate diet.

Table 2

Spearman's correlation using RBP4 as dependent variable

\begin{tabular}{llll}
\hline All groups & DM on OHG & DM + CHD & DM on diet \\
\hline Age $\left(0.17^{*}\right)$ & BMI $\left(-0.40^{*}\right)$ & Triglycerides $\left(0.38^{*}\right)$ & Systolic BP $\left(0.56^{* *}\right)$ \\
Systolic BP $\left(0.19^{*}\right)$ & Hips $\left(-0.40^{*}\right)$ & TNF- $\alpha\left(0.58^{*}\right)$ & Waist $\left(-0.66^{* *}\right)$ \\
Triglycerides $\left(0.28^{*}\right)$ & CRP $\left(-0.39^{*}\right)$ & & \\
Total cholesterol $\left(0.20^{*}\right)$ & TNF- $\alpha\left(0.52^{*}\right)$ & & \\
& LDL-cholesterol $\left(0.42^{*}\right)$ & & \\
& Total cholesterol $\left(0.35^{*}\right)$ & \\
\hline & \\
Data presented as variable $(\mathrm{R}) ;{ }^{*}$ denotes significance at $p<0.05 ;{ }^{* *}$ denotes significance at $p<0.001 ;$ \\
no significant correlations elicited for the control group.
\end{tabular}

done for RBP4 analysis on available current literature examining patients with insulin resistance. A sample size of 67 has a sufficient power $(1-\beta \geqslant 0.80, \alpha=$ $0.05)$ to detect relationships with medium effect size $(r=0.30)$ [15].

Data were expressed as mean (SD) or median (range); statistical significance was set at $p<0.05$.

\section{Results}

Table 1 summarizes the clinical and biochemical characteristics of the studied groups of type 2 diabetic subjects with or without coronary heart disease and healthy controls. In the group of diabetic subjects on oral hypoglycemic agents and diabetic patients with coronary heart disease, RBP4 plasma levels increased significantly $(30.2 \pm 11.8 ; 33.4 \pm 13.6$ respectively) compared to control group $(22.6 \pm 9.5)$ (Table 1) while there was no significant change in the other group for diabetic subjects on low-carbohydrate diet $(25.1 \pm 10.9)$. HOMA-IR was significantly increased in all studied groups compared to controls. Adiponectin levels were significantly increased in group 2 and 3 (DM on OHG and DM + CHD respectively) as opposed to control and DM on diet group. RPB4 levels were positively correlated with TNF- $\alpha$ (Table 2) in the group of diabetic subjects on oral hypoglycemic agents (Fig. 1) and diabetic patients with coronary heart disease (Fig. 2) ( $r=0.52, P<0.05 ; r=0.58, P<0.05$ respectively).

No correlations were found between RBP4 level and insulin resistance in all studied groups. Analysis of 
Table 3

Significant predictors of RBP4 using stepwise linear regression

\begin{tabular}{llll}
\hline All groups & DM on OHG & DM + CHD & DM on Diet \\
\hline Triglycerides, HDL-cholesterol, TNF- $\alpha$ & Total cholesterol, resistin, age & TNF- $\alpha$, HOMA & Adiponectin, TNF- $\alpha$ \\
$\left(\mathrm{R}^{2}=0.45 ; p<0.001\right)$ & $\left(\mathrm{R}^{2}=0.94 ; p<0.001\right)$ & $\left(\mathrm{R}^{2}=0.63 ; p=0.02\right)$ & $\left(\mathrm{R}^{2}=0.66 ; p=0.002\right)$ \\
\hline
\end{tabular}

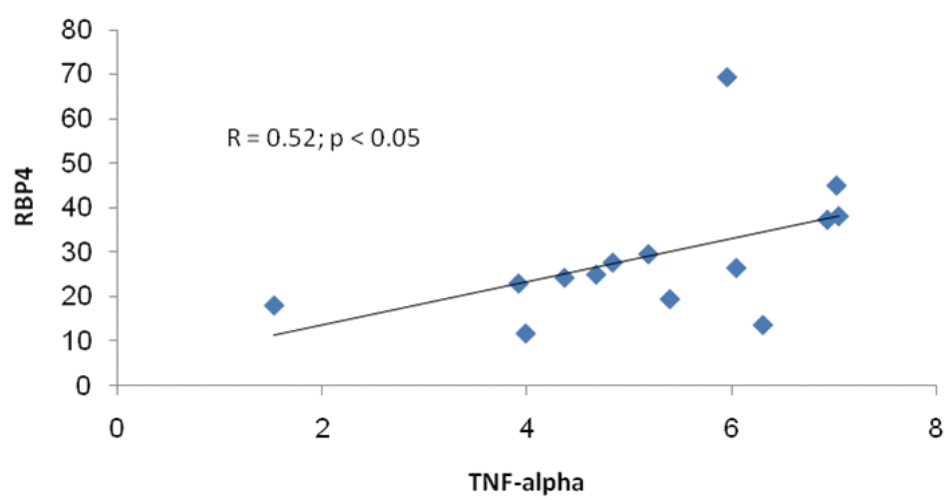

Fig. 1. Correlation between serum RBP4 and TNF- $\alpha$ in diabetic patients treated with oral hypoglycemic agents. (Colours are visible in the online version of the article at www.iospress.nl.)

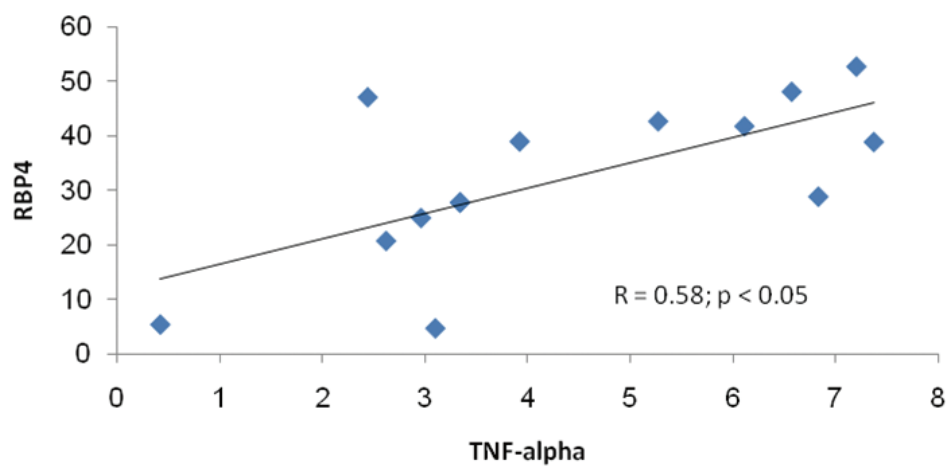

Fig. 2. Correlation between serum RBP4 and TNF- $\alpha$ in diabetic patients with coronary artery disease. (Colours are visible in the online version of the article at www.iospress.nl.)

the DM on OHG group showed a significant inverse relationship between BMI, Hips, CRP $(r=-0.4, P<$ $0.05 ; r=-0.4, P<0.05 ; r=-0.39, P<0.05$ respectively) and plasma RBP4. When all the subjects were considered for analysis there was a significant relationship between RBP4 and age $(r=0.17, P<$ $0.05)$, systolic BP $(r=0.19, P<0.05)$, triglyceride $(r=0.28, P<0.05)$, and total cholesterol $(r=0.2$, $P<0.05)$.

A stepwise linear regression analysis (Table 3) including age, gender, BMI, triglycerides, total cholesterol, LDL cholesterol, HDL cholesterol, HOMA-IR triglycerides, TNF- $\alpha$, CRP, adiponectin, leptin, and resistin as independent variables, revealed that triglycerides, HDL cholesterol and TNF- $\alpha$ were dependent contributors for increased plasma levels of RBP4 $\left(\mathrm{R}^{2}=\right.$
$0.45 ; p<0.001)$. For diabetic subjects treated with oral hypoglycemic agents; total cholesterol, resistin and age were dependent contributors for increased plasma levels of RBP4 ( $\left.\mathrm{R}^{2}=0.94 ; p<0.001\right)$. For diabetic subjects on low-carbohydrate diet; adiponectin and TNF- $\alpha$ were dependent contributors for increased plasma levels of RBP4 $\left(\mathrm{R}^{2}=0.66 ; p=0.002\right)$. While, for diabetic patients with coronary heart disease; TNF- $\alpha$, HOMA-IR were dependent contributors for increased plasma levels of RBP4 $\left(\mathrm{R}^{2}=0.63 ; p=0.02\right)$.

\section{Discussion}

The present study is the first to investigate RBP4 plasma levels in diabetic patients differentiated accord- 
ing to the type of treatment (either oral hypoglycemic drugs or low carbohydrate diet). A striking observation of our study was that in the group of diabetic patients treated with oral hypoglycemic drugs and diabetic patients with coronary heart disease, RBP4 levels increased significantly while in the group of diabetic patients treated with low carbohydrate diet RBP4 levels was similar to that of controls. Our data suggest that low-carbohydrate diet is useful in lowering RPB4 levels in diabetic patients. Recently, it has been observed that exercise and weight loss have been reported to decrease both RBP4 levels and insulin resistance [7]. Similarly it has been observed that plasma levels and adipose tissue mRNA expression of retinolbinding protein 4 are reduced during calorie restriction in obese subjects [16].

RBP4 is a member of the lipocalin protein family. This is a group of proteins with a rather small molecular weight that have been studied as biomarkers of different diseases [17]. The adipokine RBP4 has recently been shown to link obesity and insulin resistance in rodents [7]. In humans, however, the role of RBP4 is still controversial. Some previous studies demonstrated that RBP4 is associated with insulin resistance [7, $10,18]$; and that single nucleotide polymorphism in the RBP4 gene is also associated with type 2 diabetes in human subjects [19], on the other hand, some reports have revealed that the RBP4 level is not correlated with obesity [20]. Recently, a three year longitudinal study also showed that plasma retinol-binding protein is not a marker of insulin resistance in overweight subjects [21]. Our results were in accordance with previous studies showing no correlation between RPB4 and insulin resistance. The lack of association suggests other factors not included in this study such as renal function, as it was reported that renal insufficiency is the causative mechanism that elevates RBP4 levels among diabetics and not necessarily obesity and insulin resistance [22]. Furthermore, it was reported that plasma RBP-4 gene expression is associated with GLUT4 mRNA expression in adipose tissue and not with insulin resistance [8]. Renal function together with insulin resistance is affected with advancing age, which can also explain the lack of association among the younger control group in this study.

Treatment with thiazolidinediones has been shown to consistently increase levels of adiponectin [23]. This explains why the adiponectin levels in group 2 and 3 (DM on OHG and DM + CHD respectively) were elevated as opposed to control and DM on diet group.

There is some evidence that tumor necrosis factora $(\mathrm{TNF}-\alpha)$ expression is increased in the muscle and adipose tissue of obese humans and patients with type 2 diabetes when compared with lean individuals [2426], although not all studies are concordant [27]. It has been shown that TNF- $\alpha$ strongly down regulates RBP4 production in adipocytes [13], a completely unexpected effect, as TNF- $\alpha$-treated adipocytes are insulin resistant [28]. Our results showed positive correlation between RBP4 and TNF- $\alpha$ in the studied groups which have significant higher levels of RBP4 compared to controls (diabetic subjects on oral hypoglycemic agents and diabetic patients with coronary heart disease). Consistent with our results, it has recently been shown that adipose tissue RBP mRNA levels correlated positively with levels of TNF- $\alpha$ mRNA of plasma and skeletal muscle origin, suggesting that TNF-alpha may have a role in RBP-mediated adipose to muscle cross talk [29].

It was reported that quantitative western blotting reports RBP4 concentrations with the least overlap between insulin-sensitive and insulin-resistant subjects. Although sandwich ELISA reports RBP4 concentrations that inversely correlate with insulin resistance, but values in normal subjects are higher than expected [30]. The authors acknowledge several limitations such as lack of cross validation of the ELISA method used in measuring RBP4 levels using quantitative western blotting, the absence of measurement of adipocytokines and inflammatory markers for patients on baseline before taking any treatment or having low carbohydrate diet. Although the sample sizes were adequate for the analyses undertaken, a much larger population would be required to assess RBP4 levels in patients with coronary heart disease. Also, due to small sample size, subjects in the studied groups were not age matched. In conclusion, our findings suggest that serum RBP4 levels are associated with pro-inflammatory cytokine (TNF- $\alpha$ ) and not with insulin resistance among patients with type 2 diabetes and coronary heart disease.

\section{Acknowledgement}

The authors would like to thank the College of Science Research Center in King Saud University, Riyadh, (Bio/2009/08) for financing this study.

\section{References}

[1] S.M. Grundy, Obesity, metabolic syndrome, and cardiovascular disease, J Clin Endocrinol Metab 89 (2004), 2595-2600.

[2] R. Beetham, A. Silver and A. Dawnay, Urinary albumin and retinol-binding protein in diabetes, Clin Chem 33 (1987), 713. 
[3] Q. Yang, T.E. Graham, N. Mody, F. Preitner, O.D. Peroni, J.M Zabalotny, K. Kotani, L. Quadro and B.B. Khan, Serum retinol binding protein 4 contributes to insulin resistance in obesity and type 2 diabetes, Nature 436(7049) (2005), 356-362.

[4] Y. Tamori, H. Sakaue and M. Kasuga, RBP4, an unexpected adipokine, Nat Med 12 (2006), 30-31.

[5] C.G. Basualdo, E.E. Wein and T.K. Basu, Vitamin A (retinol) status of first nation adults with non insulin-dependent diabetes mellitus, J Am Coll Nutr 16 (1997), 39-45.

[6] M.A. Abahusain, J. Wright, J.W. Dickerson and E.B. de Vol, Retinol, alphatocopherol and carotenoids in diabetes, Eur J Clin Nutr 53 (1999), 630-635.

[7] T.E. Graham, Q Yang, M, Bluher, A. Hammarstedt, T.P. Ciaraldi, R.R. Henry, C.J. Wason, A. Oberbac, P.A. Jansson, U. Smith and B.B. Kahn, Retinol-binding protein 4 and insulin resistance in lean, obese, and diabetic subjects, $N$ Engl $\mathrm{J} \mathrm{Med}$ 354 (2006), 2552-2563.

[8] J. Janke, S. Engeli, M. Boschmann, F. Adams, J. Bohnke, F.C. Luft, A.M. Sharma and J. Jordan, Retinol-binding protein 4 in human obesity, Diabetes 55 (2006), 2805-2810.

[9] C. Erikstrup, O.H. Mortensen and B.K. Pedersen, Retinolbinding protein 4 and insulin resistance, $N$ Engl J Med 355 (2006), 1393-1394.

[10] Y.M. Cho, B.S. Youn, H. Lee, N. Lee, S.S Min, S.H. Kwak, H.K Lee and K.S. Park, Plasma retinol binding protein-4 concentrations are elevated in human subjects with impaired glucose tolerance and type 2 diabetes, Diabetes Care 29 (2006), 2457-2461.

[11] M. von Eynatten, P.M. Lepper, D. Liu, K. Lang, M. Baumann, P.P. Nawroth, A. Bierhaus, K.A. Dugi, U. Heemann, B. Allolio and P.M. Humpert, Retinol-binding protein 4 is associated with components of the metabolic syndrome, but not with insulin resistance, in men with type 2 diabetes or coronary artery disease, Diabetologia 50 (2007), 1930-1937.

[12] G.S. Hotamisligil, N.S. Shargill and B.M. Spiegelman, Adipose expression of tumor necrosis factor- $\alpha$ : direct role in obesity-linked insulin resistance, Science 259 (1993), 87-91.

[13] H. Sell and J. Eckel, Regulation of retinol binding protein 4 production in primary human adipocytes by adiponectin, troglitazone and TNF-alpha, Diabetologia 50(10) (2007), 2221-2223.

[14] D.R. Matthews, A.S. Rudenski, B.A. Naylor, D.F. Treacher and R.C. Turner, Homeostasis model assessment: insulin resistance and beta-cell function from fasting plasma glucose and insulin concentrations in man, Diabetologia 28(7) (1985), 412-419.

[15] I. Kowalska, M. Straczkowski, A. Adamska, A. Nikolajuk, M. Karczewska-Kupczewska, E. Otziomek and M. Gorska, Serum retinol binding protein 4 is related to insulin resistance and nonoxidative glucose metabolism in lean and obese women with normal glucose tolerance, J Clin Endocrinol Metab 93(7) (2008), 2786-2789.

[16] M. Vitkova, E. Klimcakova, M. Kovacikova, C. Valle, C. Moro, J. Polak, J. Hanacek, F. Capel, N. Viguerie, B. Richterova, M. Bajzova, J. Hejnova, V. Stich and D. Langin, Plasma levels and adipose tissue messenger ribonucleic acid expression of retinol-binding protein 4 are reduced during calorie restriction in obese subjects but are not related to diet-induced changes in insulin sensitivity, J Clin Endocrinol Metab 92(6) (2007), 2330-2335.
[17] S. Xu and P. Venge, Lipocalins as biochemical markers of disease, Biochim Biophys Acta 1482 (2000), 298-307.

[18] S. Gavi, L.M. Stuart, P. Kelly, M.M. Melendez, D.C. Mynarcik, M.C. Gelato and M.A. McNurlan, Retinol-binding protein 4 is associated with insulin resistance and body fat distribution in nonobese subjects without type 2 diabetes, $J$ Clin Endocrinol Metab 92 (2007), 1886-1890.

[19] L. Munkhtulga, K. Nakayama, N. Utsumi, Y. Yanagisawa, T. Gotoh, T. Omi, M. Kumada, B. Erdenebulgan, K. Zolzaya, T. Lkhagvasuren and S. Iwamoto, Identification of a regulatory SNP in the retinol binding protein 4 gene associated with type 2 diabetes in Mongolia, Hum Genet 120 (2007), 879-888.

[20] N. Takashima, H. Tomoike and N. Iwai, Retinol-binding protein 4 and insulin resistance, $N$ Engl J Med 355 (2006), 1392.

[21] J.G. Lewis, B.I. Shand, C.M. Frampton, P.A. Elder and R.S. Scott, Plasma retinol-binding protein is not a marker of insulin resistance in overweight subjects: a three year longitudinal study, Clin Biochem 41(13) (2008), 1034-1038.

[22] A. Henze, S.K. Frey, J. Raila, M. Tepe, A. Scholze, A.F. Pfeiffer, M.O. Weickert, J. Spranger and F.J. Schweigert, Evidence that kidney function but not type 2 diabetes mellitus determines retinol-binding protein 4 (RBP4) serum levels, Diabetes 57(12) (2008), 3323-3326.

[23] J. Rosenstock, J. Rood, A. Cobitz, N. Biswas, H. Chou and A. Garber, Initial treatment with rosiglitazone/metformin fixeddose therapy compared with monotherapy with either rosiglitazone or metformin in patients with uncontrolled type 2 diabetes, Diabetes, Obesity and Metabolism 8 (2006), 650-660.

[24] P.A. Kern, M. Saghizadeh, J.M. Ong, R.J. Bosch, R. Deem and R.B. Simsolo, The expression of tumor necrosis factor in human adipose tisssue. Regulation by obesity, weight loss, and relationship to lipoprotein lipase, J Clin Invest 95 (1995), 2111-2119.

[25] G.S. Hotamisligil, P. Peraldi, A. Budavari, R. Ellis, M.F. White and B.M. Spiegelman, IRS1 mediated inhibition of insulin receptor tyrosine kinase activity in TNF-a- and obesity-induced insulin resistance, Science 271 (1996), 665-668.

[26] M. Saghizadeh, J.M. Ong, W.T. Garvey, R.R. Henry and P.A Kern, The expression of TNFa by human muscle. Relationship to insulin resistance, J Clin Invest 97 (1996), 1111-1116.

[27] H.A. Koistinen, J.P. Bastard, E. Dusserre, P. Ebeling, N. Zegari, F. Andreelli, C. Jardel, M. Donner, L. Meyer, P. Moulin, B. Hainque, J.P. Riou, M. Laville, V.A. Koivisto and H. Vidal, Subcutaneous adipose tissue expression of tumour necrosis factor-alpha is not associated with whole body insulin resistance in obese nondiabetic or in type-2 diabetic subjects, Eur J Clin Invest 30 (2000), 302-310.

[28] L.S. Liu, M. Spelleken, K. Rohrig, H. Hauner and J. Eckel, Tumor necrosis factor-alpha acutely inhibits insulin signaling in human adipocytes: implication of the p80 tumor necrosis factor receptor, Diabetes 47 (1998), 515-522.

[29] C. Erikstrup, O.H. Mortensen, A.R. Nielsen, C.P. Fischer, P. Plomgaard, A.M. Petersen, R. Krogh-Madsen, B. Lindegaard, J.G. Erhardt, H. Ullum, C.S. Benn and B.K. Pedersen, RBP-toretinol ratio, but not total $\mathrm{RBP}$, is elevated in patients with type 2 diabetes, Diabetes, Obesity and Metabolism 11(3), 204-212.

[30] T.E. Graham, C.J. Wason, M. Blüher and B.B. Kahn, Shortcomings in methodology complicate measurements of serum retinol binding protein (RBP4) in insulin-resistant human subjects, Diabetologia, 50(4) (2007), 814-23 


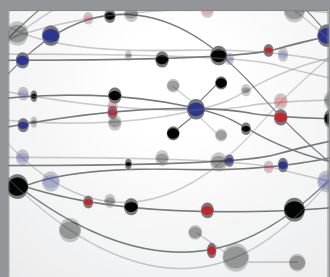

The Scientific World Journal
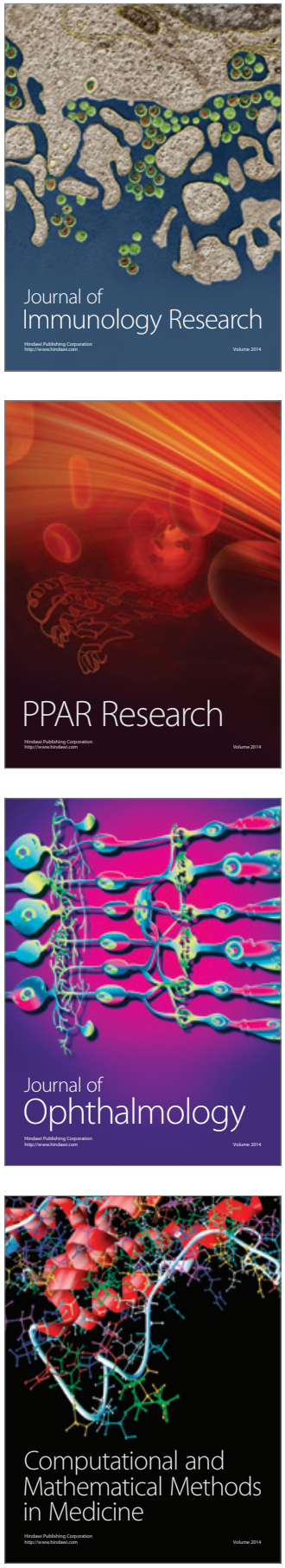

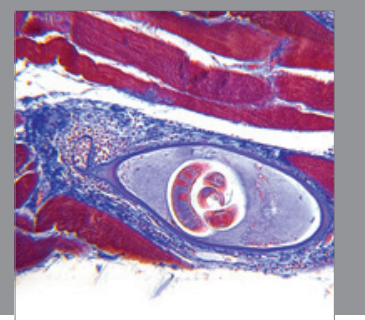

Gastroenterology

Research and Practice
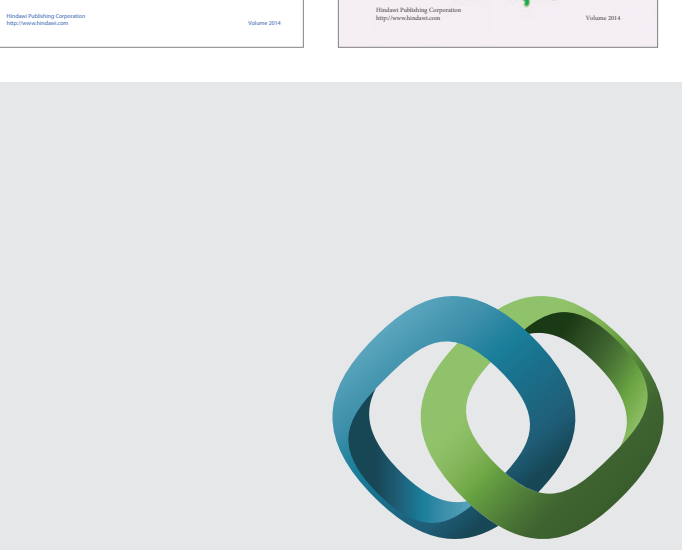

\section{Hindawi}

Submit your manuscripts at

http://www.hindawi.com
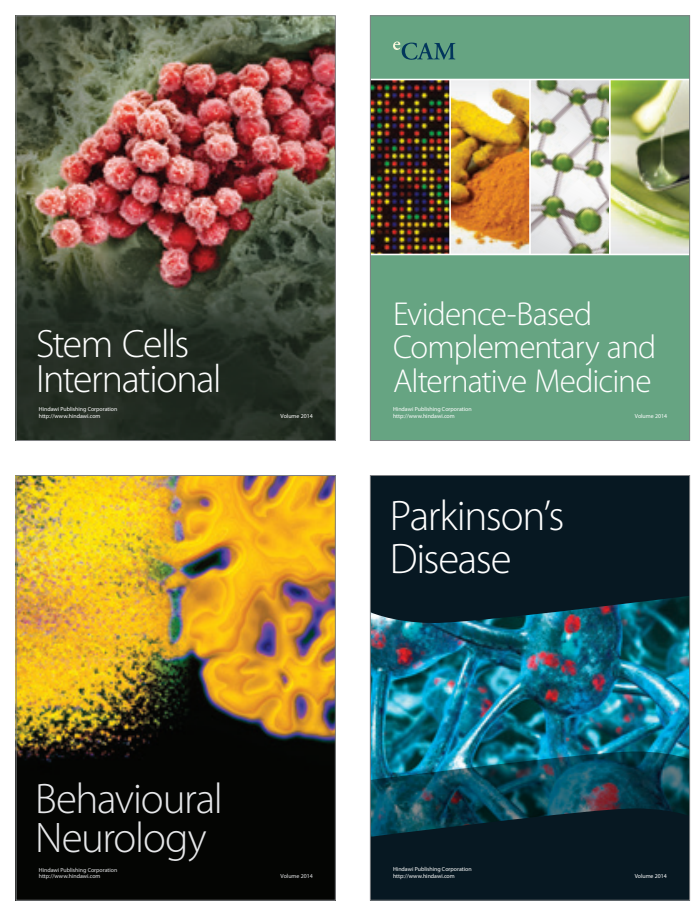

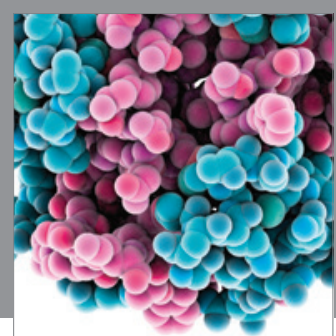

Journal of
Diabetes Research

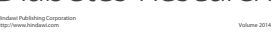

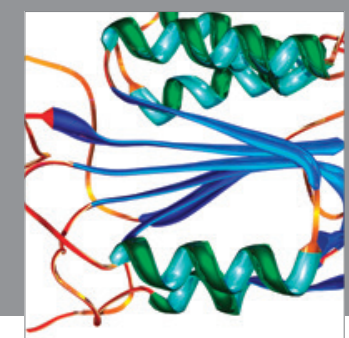

Disease Markers
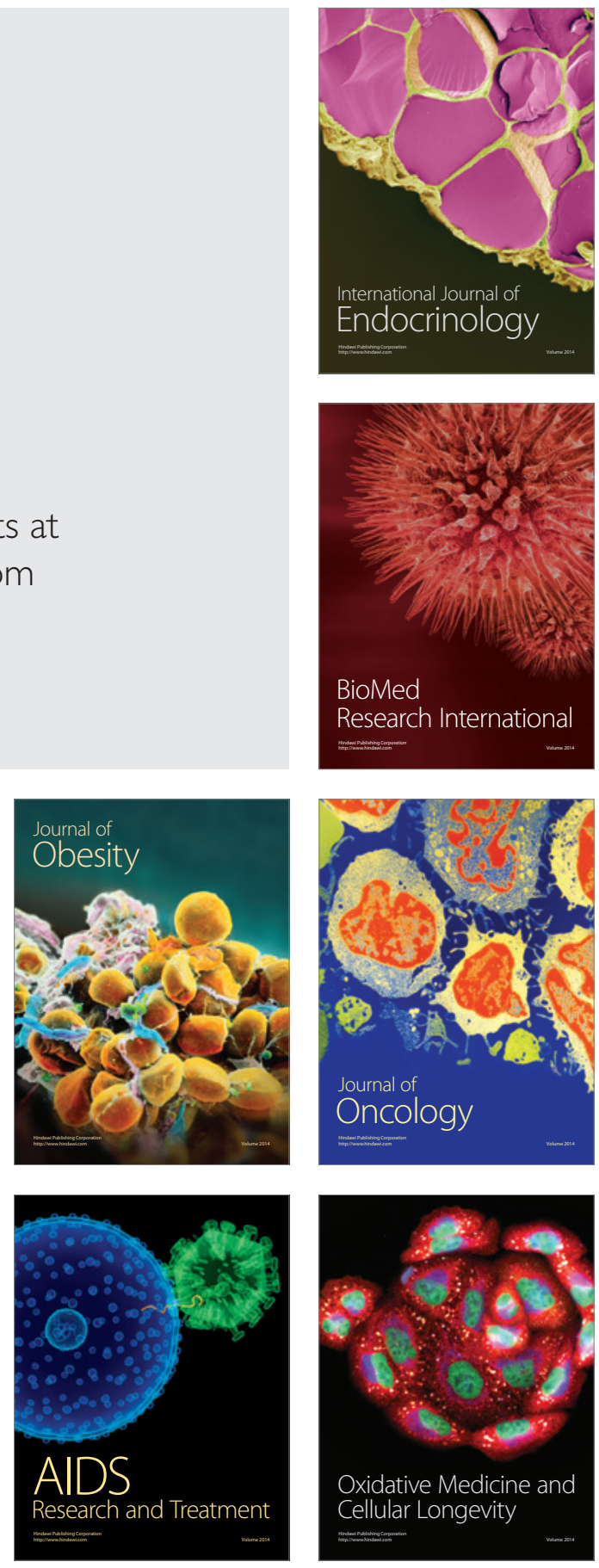